\title{
VI. THE ROLE OF PHYSICAL ACTIVITY IN REDUCING BARRIERS TO LEARNING IN CHILDREN WITH DEVELOPMENTAL DISORDERS
}

\author{
Matthew B. Pontifex, Jodene G. Fine, Katelin da Cruz, Andrew C. Parks, \\ and Alan L. Smith
}

\begin{abstract}
Emerging research suggests that physical activity may be an effective non-pharmaceutical intervention approach for childhood developmental disorders. Findings indicate that both single bouts of activity and chronic physical activity associate with improved mental health and classroom performance in children with attention-deficit/hyperactivity disorder and children with autism spectrum disorders. This review describes the research in this area and identifies limitations and challenges to the translation of these findings to promote physical activity in clinical practice and educational policy.
\end{abstract}

Concomitant with the pervasiveness of developmental neurobehavioral disorders, trends indicate decreasing participation in physical activity behaviors during childhood (DHHS and DOE, 2000). In particular, children with developmental disorders, such as attention-deficit/hyperactivity disorder (ADHD) and autism spectrum disorders (ASD) have been found to exhibit lower physical activity participation levels than the general pediatric population (Kim, Mutyala, Agiovlasitis, \& Fernhall, 2011; Pan \& Frey, 2006). As a growing body of evidence has demonstrated a beneficial relation between physical activity and cognitive health in preadolescent children (Castelli, Hillman, Buck, \& Erwin, 2007; Hillman, Buck, Themanson, Pontifex, \& Castelli, 2009; Kamijo et al., 2011; Pontifex et al., 2011; Pontifex, Scudder, Drollette, \& Hillman, 2012; Sibley \& Etnier, 2003; Tomporowski, 2003), a greater understanding of the extent to which physical activity may alter developmental trajectories of mental health is of increasing importance. Accordingly, this review describes the extant literature on the influence of both acute and chronic physical activity participation on mental health and

Corresponding author: Matthew B. Pontifex, Department of Kinesiology, Michigan State University, 27P IM Sports Circle, 308 W. Circle Dr., East Lansing, MI 48824-1049, email: pontifex@msu.edu 
scholastic performance in children with developmental disorders and articulates challenges to overcome in order to advance this area of study.

\section{ATTENTION-DEFICIT/HYPERACTIVITY DISORDER}

ADHD is a chronic neurobehavioral disorder characterized by inattention, over-activity, distractibility, and impulsiveness manifesting as a childhood-onset disorder (American Psychiatric Association, 2013; Banaschewski et al., 2006; Schachar, Mota, Logan, Tannock, \& Klim, 2000). Although it is normal for children to exhibit the behaviors that define ADHD, children with ADHD disproportionately express these behaviors compared to typically developing children of the same age. This results in substantial impairments in daily functioning. According to the Diagnostic and Statistical Manual of Mental Disorders (DSM-5; American Psychiatric Association, 2013) these symptoms should occur in two or more settings (e.g., both home and school), must be present for more than 6 months, and show onset before the age of 12 years. ADHD diagnoses are categorized into three subtypes: predominately inattentive (ADHD-I), predominately hyperactive/impulsive (ADHD-H), and a subtype combining symptoms of inattention and hyperactivity/impulsivity (ADHD-C). The ADHD-H subgroup is typically observed among children of preschool age, when the hyperactive-impulsive behavior pattern first emerges (Applegate et al., 1997). Symptoms of inattention appear to have later onsets, with ADHD-I and ADHD-C predominately occurring during the school-aged years (Hart, Lahey, Loeber, Applegate, \& Frick, 1995; Loeber, Green, Lahey, Christ, \& Frick, 1992). The ADHD-I subgroup (formerly classified as attention-deficit disorder [ADD]) is characterized by developmentally inappropriate behaviors such as failing to attend and follow directions, having difficulty sustaining attention and organizing activities, and being easily distracted and forgetful (Barkley, DuPaul, \& McMurray, 1990; Bracken \& Boatwright, 2005).

The CDC reports an $\mathrm{ADHD}$ prevalence rate of about $8 \%$, suggesting that approximately five million children aged 3-17 years of age are affected by the disorder (Bloom, Cohen, \& Freeman, 2010). Prevalence estimates of ADHD are heterogeneous, likely resulting from varying methodological characteristics of epidemiological studies (Polanczyk, Silva de Lima, Horta, Biederman, \& Rohde, 2007). Nonetheless, the National Health Interview Survey reports an average 3\% annual increase in lifetime diagnosis of ADHD between 1997 and 2006, and an estimated one million more children diagnosed with ADHD in 2007 than in 2003 (Pastor \& Reuben, 2008). Lower quality of interpersonal relationships have also been observed along with less perceived family cohesiveness and greater conflict, parent depression, and incidence of 
separation (Brown \& Pacini, 1989) along with lower parent work status and productivity (Noe \& Hankin, 2001). In addition to family challenges, ADHD is associated with increased developmental risk for early substance experimentation and abuse, anxiety, depression, and aggression in children diagnosed with the disorder (Barkley, Guevremont, Anastopoulos, DuPaul, \& Shelton, 1993; Biederman, Wilens, Mick, Faraone, \& Spencer, 1998; Pomerleau, Downey, Stelson, \& Pomerleau, 1995). Finally, ADHD appears to persist into adulthood, though symptoms may change over time (Martel, von Eye, \& Nigg, 2012).

\section{Single Bouts of Physical Activity as a Tool in the Treatment of ADHD}

Given the economic burden and prevalence of ADHD, there has been an increased focus on developing efficacious treatment strategies. Pharmacological treatments using psychostimulants have been found effective in the short-term treatment of behavioral symptoms of ADHD (Solanto, Arnsten, \& Castellanos, 2001). However, long-term implications of psychostimulant use have yet to be fully addressed (Moll, Hause, Rüther, Rothenberger, \& Huether, 2001; Wilson \& Jennings, 1996) and many parents have reservations about pharmacological treatment because of concerns about potential shortterm side effects, long-term effects, negative information from the lay press, and personal views on the ubiquity of medication use (Berger, Dor, Nevo, \& Goldzweig, 2008; dosReis et al., 2003). Thus, parents are increasingly willing to investigate alternative treatments for ADHD, particularly those that do not include medication administration (Wilson \& Jennings, 1996). A growing body of research suggests that employing physical activity bouts may be an efficacious strategy for children with ADHD.

Two case studies highlight the potential utility of single bouts of exercise for reducing symptomology and behavioral disruptions within the classroom. Etscheidt and Ayllon (1987) asked a 13-year-old boy who exhibited symptoms of hyperactivity and distractibility to engage in moderate-to-vigorous levels of activity for a short duration (5-15 min) whenever he recognized he was exhibiting disruptive behaviors. Following such activity, the boy was observed to exhibit greater attentiveness in the classroom. Similarly, Azrin, Ehle, and Beaumont (2006) observed the effects of regular physical activity breaks on the behavior of an unmedicated 4-year-old boy with ADHD and comorbid symptoms of autism. The child exhibited enhanced attentiveness and reduced hyperactivity when provided with regular access to playground equipment to engage in vigorous activity; an effect not observed following other intervention strategies such as concurrent praise (Azrin et al., 2006). In addition to these case studies, Medina and colleagues (2010) observed greater sustained attention and decreased impulsivity using a continuous performance task in a sample of 25 boys diagnosed with ADHD following $30 \mathrm{~min}$ of 
high-intensity aerobic exercise. These improvements were attained regardless of medication status.

However, findings have not been universally positive within this small body of research. Craft (1983) utilized a sample of 31 ADHD and 31 healthy-match control boys between the ages of 7 and 10 years to examine the cognitive effects of 1, 5, and $10 \mathrm{~min}$ of cycling on a stationary ergometer. Findings revealed no differences in cognition, as measured by the Wechsler Intelligence Scale for Children-Revised (WISC-R; Wechsler, 1974), and the Digit Span and Coding B subtests of the Illinois Test of Psycholinguistic Abilities (ITPA; Kirk, McCarthy, \& Kirk, 1968) for either the ADHD or healthy control participants. It is possible that the exercise bouts were of insufficient duration to alter cognition. The exercise modality (i.e., cycling) may also have been poorly chosen for this age group. Preadolescent children have underdeveloped knee extensor muscles, resulting in localized muscular fatigue and exhaustion following pedaling on a cycle at resistance (Bar-Or, 1983). This could prevent children from maintaining sufficient exercise intensity over the length of the longer 10-min cycling condition to incur potential benefits. Craft (1983) noted that the majority of participants exhibited signs of exhaustion at the 10-min mark, providing additional support for this view. To date, limited empirical evidence is available to suggest the specific characteristics of exercise necessary to incur cognitive benefits.

A recent study that mirrored the mode, duration, and intensity of previous work in healthy children (Hillman, Pontifex, et al., 2009) and adults (Hillman, Snook, \& Jerome, 2003), supports a positive association between exercise and acute changes in cognitive functioning in children with ADHD. Pontifex, Saliba, Raine, Picchietti, and Hillman (2013) examined the effect of a single bout of $20 \mathrm{~min}$ of moderately intense aerobic exercise on a motor driven treadmill on inhibitory control and scholastic performance in 20 preadolescent children with ADHD and a similarly sized match-control group, relative to a seated reading control condition. Inhibitory control is a component in a set of higher-order cognitive operations known as cognitive control that allow for the optimization of behavior through the selection, scheduling, coordination, and maintenance of computational processes that underlie aspects of perception, memory, and action (Botvinick, Braver, Barch, Carter, \& Cohen, 2001; Meyer \& Kieras, 1997; Miyake, Friedman, Emerson, Witzki, \& Howerter, 2000; Norman \& Shallice, 1986). Inhibitory control allows for one to deliberately override a dominant or overlearned response in order to perform a less potent but correct response, to suppress task-irrelevant information in the stimulus environment, and to override an ongoing response (Barkley, 1997; Davidson, Amso, Anderson, \& Diamond, 2006).

Deficits in inhibition have consistently been observed (i.e., decreased response accuracy, longer and more variable reaction time) in previous investigations into ADHD across a variety of tasks (e.g., flanker, Go/No-Go, 
Stroop) (Albrecht et al., 2008; Booth, Carlson, \& Tucker, 2007; Castellanos et al., 2000; Crone, Jennings, \& Van Der Molen, 2003; Hartung, Milich, Lynam, \& Martin, 2002; Iaboni, Douglas, \& Baker, 1995; Jonkman et al., 1999; Konrad, Neufang, Hanisch, Fink, \& Herpertz-Dahlmann, 2006; Vaidya et al., 1998; Vaidya et al. 2005). Further, meta-analyses indicate moderate effect sizes for ADHD-related deficits in inhibitory control ranging from .54 to .75 (Homack \& Riccio, 2004; Pennington \& Ozonoff, 1996; Willcutt, Doyle, Nigg, Faraone, \& Pennington, 2005). Interestingly, investigations into the effects of acute exercise and inhibitory control in both healthy children and young adults have observed improvements in performance on tasks that tap aspects of inhibition (i.e., flanker, Stroop, and the Paced Auditory Serial Addition Test) following participation in a single bout of structured physical activities lasting at least $20 \mathrm{~min}$ (Hillman, Buck, et al., 2009; Hillman et al., 2003; Hogervorst, Riedel, Jeukendrup, \& Jolles, 1996; Kamijo, Nishihira, Higashiura, \& Kuroiwa, 2007; Lichtman \& Poser, 1983; Sibley, Etnier, \& Le Masurier, 2006; Tomporowski et al., 2005). Consistent with these findings, Pontifex et al. (2013) observed enhancements in inhibitory control and the allocation of attentional resources (as indexed by increases in the amplitude of the P3 ERP component; see Chapter 3) as well as improvements in the areas of reading and arithmetic in both children with ADHD and healthy matchcontrols. This offers evidence that single bouts of exercise may be used to target core cognitive deficits that may underlie behavioral dysfunctions and create barriers to learning in children with ADHD (Barkley, 1997).

\section{ADHD and Chronic Physical Activity Behaviors}

Although physical activity often occurs in single "doses" of exercise (similar to the way in which medication is administered), exercise offers the unique opportunity to create more long-term changes in ADHD symptomology. That is, unlike the effects of current pharmacologic therapies, which require regular dosing, more enduring enhancements in cognition associated with chronic physical activity participation may result from progressive accrual of repeated bouts of exercise. Research utilizing animal models has begun to demonstrate a positive association between chronic physical activity during adolescent periods and behavior in rodent analogs of ADHD. For example, Panksepp, Burgdorf, Turner, and Gordon (2003) observed that an extra hour per day of play activity was effective in reducing impulsivity in rats lesioned to exhibit ADHD-like symptoms. More recently, Robinson, Hopkins, and Bucci (2011) observed that voluntary wheel-running in spontaneously hypertensive rats was associated with reduced distractibility and improved attention relative to sedentary spontaneously hypertensive rats; with resulting behavioral levels similar to those exhibited by control rats. In human models, early evidence points to potential benefits of chronic physical activity 
participation for children with ADHD. For example, in a cross-sectional investigation of boys ages-12 years receiving pharmacological treatment for $\mathrm{ADHD}$, time spent in moderate-to-vigorous physical activity over a 7-day period was associated with better performance on tests of cognitive control (Gapin \& Etnier, 2010). This work shows a potential link between chronic activity patterns and cognitive function in children with ADHD that warrants closer examination through assessment of physical activity programming.

A few studies have employed physical activity programming as a primary tool for addressing ADHD symptoms in children. Smith et al. (2013) piloted a before-school physical activity intervention in a sample of medication naïve children ages 5-8 years at risk for ADHD based on expression of hyperactivity/impulsivity symptoms. Participants completed a morning program every school day for 8 weeks that exposed children to approximately $26 \mathrm{~min}$ of continuous moderate-to-vigorous physical activity per session. Reductions were observed in the inattention/overactivity and oppositional/ defiant Iowa Conners (Loney \& Milich, 1982) subscales as were improvements in inhibition and peer interactions. A control group was not utilized in this pilot investigation, requiring caution in forwarding conclusions about benefits unique to children with ADHD or independent of normal maturational change. Indeed, McKune, Pautz, and Lombard (2003) observed improvements in the behaviors of children with ADHD as measured by the Conners' Parent Rating Scale (Goyette, Conners, \& Ulrich, 1978) for both those exposed to a 5-week afternoon exercise intervention and those in a nonexercise control group. Another study, however, examining children ages 712 years diagnosed with ADHD demonstrated group differences between those exposed to a 45-min physical activity program 3 days per week over 10 weeks and control participants (Verret, Guay, Berthiaume, Gardiner, \& Béliveau, 2012). Specifically, those in the physical activity group showed enhancements in information processing, visual search, and sustained attention as well as reductions in social, thought, and attentional problems as compared to controls (Verret et al., 2012). It is possible that longer physical activity exposure is necessary to demonstrate group differences, but this will require more systematic investigation in light of the limited database and shortcomings tied to group assignment in these particular studies. These limitations noted, there is reasonable, collective evidence to justify more intensive investigation of chronic physical activity as a potential intervention strategy for producing enduring enhancements in cognitive and behavioral manifestations of ADHD during development.

\section{Challenges and Limitations of Promoting Physical Activity in Children With ADHD}

Despite growing evidence for a beneficial relation between physical activity and ADHD symptomology, several critical limitations present barriers 
to the promotion of physical activity in clinical practice or educational policy. Promotion of such interventions is premature, given that the specific characteristics and conditions of physical activity on cognitive and scholastic performance in children with ADHD are not fully understood. Analogous to the quantification of the effects of psychostimulants on children with ADHD, continued research will offer evidence-based recommendations to influence clinical and educational policies. Additionally, there is little understanding of how various types of physical activity may differentially influence cognition and scholastic performance of children with ADHD relative to their typically developing peers. Such knowledge of the influence of various parameters of physical activity (mode, frequency, intensity, duration) as well as the half-life of resultant cognitive and behavioral enhancements is necessary to understand in order to best compare effects to more traditional treatment strategies for ADHD. This will enable examination of the transition from acute exercise-induced enhancements to the more long-lasting enhancements observed with chronic physical activity behaviors. Overall, addressing these matters will allow for optimization of immediate benefits while more rapidly incurring stable changes in behavior.

Recent findings suggest that physical activity also occurs less frequently in children with ADHD, posing a challenge to employing physical activity interventions. For example, Kim, Heo, et al. (2011) conducted a crosssectional analysis of children age 6-17 years included within the 2003 National Survey of Children's Health, and found that children with ADHD were less engaged in physical activity and organized sports than their peers. It will therefore be important to determine the antecedents of and barriers to physical activity behaviors in children with ADHD in order to develop best practice recommendations for engaging this population. Because of the potential value of physical activity for enhancing mental health and scholastic performance in children with ADHD, careful consideration of best practice methods to utilize this non-pharmaceutical treatment option for this population is warranted.

\section{AUTISM SPECTRUM DISORDERS}

Autism Spectrum Disorders (ASDs) are a group of developmental disabilities characterized by impairments across two domains of functioning based on the DSM-5 (American Psychiatric Association, 2013). Specifically, individuals with ASD exhibit deficits in social and communicative interaction and restrictive or repetitive patterns of behavior and/or interests. Social reciprocity, perspective-taking, and deficits in nonverbal communication and in building flexibly appropriate social relationships are seen in children with ASD. Impairments in communication may range from failure to acquire 
any speech, a need for alternative communication methods, use of stereotyped speech, echolalia, and/or simply having difficulty following typical rules of conversation. Individuals with ASD can exhibit repetitive movements or utterances, repetitive use of objects, unusual or all-consuming interests, and compulsive, rigid, ritualistic behaviors such as insisting on sameness. Impairments are typically present within an early developmental period, although many high functioning persons with an ASD are not diagnosed until much later, when social demands exceed their capacity. Atypical development of cognitive functioning, learning, attention, and sensory processing are also associated with ASD (Rice, 2009). The phrase "spectrum disorders" is used to indicate that ASDs encompass a range of behaviorally defined conditions including those previously referred to as Asperger disorder, and Pervasive Developmental Disorder-Not Otherwise Specified (PDD-NOS).

In 2000, the CDC organized the Autism and Developmental Disabilities Monitoring Network to provide a better understanding of the prevalence and public health impact of ASD in the United States. Using a multiplesource, records-based surveillance methodology to conduct retrospective review of data from multiple education and health facilities, the best estimate of ASD prevalence is approximately 1 in every 88 children in the United States (Rice, 2009). Most troubling is that the prevalence of ASD has increased by $23 \%$ since 2006 and $78 \%$ since 2002 according to data from the Autism and Developmental Disabilities Monitoring Network (Baio, 2012). Whereas such dramatic increases in prevalence in a relatively short period of time likely reflect a combination of broadening diagnostic concepts, greater awareness and accessing of services, refinement in methodology, as well as a true increase in prevalence of ASD symptoms; these data speak to the potential public health burden of this neurobehavioral disorder (Baio, 2012).

Preliminary findings from research funded by Autism Speaks, a leading autism science and advocacy organization, suggest that ASD has a societal cost of over $\$ 125$ billion per year, triple the cost present in 2006 , with $95 \%$ of these costs subsidized by state and federal governments (Knapp, Romeo, \& Beecham, 2009). Beyond economic burdens, caregivers of individuals with ASD also incur burdens related to disruption of routines, time and energy spent dealing with the health care system, negative interactions with service providers, neglect of self and other family member needs, restriction of social activities, and impaired relations with non-family members (Khanna et al., 2011). Unsurprisingly, several studies show caregivers of children with autism to have greater stress, anxiety, and depression than parents of typically developing children or children with other developmental disorders (Abbeduto et al., 2004; Hastings \& Johnson, 2001; Smith, Seltzer, TagerFlusberg, Greenberg, \& Carter, 2008). 


\section{Single Bouts of Physical Activity as a Tool in the Treatment of ASD}

Non-pharmaceutical management strategies for ASD have predominately focused on stimulating the development of skills related to cognition, language, and social interaction, and the suppression of negative behavioral patterns such as rigidity and stereotypical movements (Koenig et al., 2010). Given previous research in neurotypical participant populations, which has observed positive relations between physical activity behaviors and some of these factors, physical activity may serve as an effective supplement to treatment. A recent review (Lang et al., 2010) examined 18 studies of the effects of single bouts of physical activity-predominately jogging and aerobic activities - on individuals diagnosed with ASD. Acute bouts of physical activity were found to be effective in reducing stereotypical behaviors associated with ASD and enhancing classroom behaviors. For example, a small preliminary study by Kern, Koegel, and Dunlap (1984) examined the effects of different types of exercise on stereotypical mannerisms (i.e., intense staring, nasal vocalizations, flapping of fingers/hands/arms, jerking or shaking of body, and forward and backward rocking) in three children (aged 7, 11, and 11 years) with autism. The experimental protocol involved alternating $15 \mathrm{~min}$ of two different types of physical activity with 90-min periods of observation. Findings revealed a $26 \%$ decrease in stereotypic responding following $15 \mathrm{~min}$ of mildly strenuous jogging, but not ball throwing, with stereotypic responding decreasing below baseline levels after each bout of jogging (Kern et al., 1984). Utilizing a similar research design, Celiberti, Bobo, Kelly, Harris, and Handleman (1997) observed a 31\% reduction in physical selfstimulation behaviors in a single 5-year, 9-month-old participant with mild to moderate autism following just 5 min of moderate intensity jogging. Selfstimulating behaviors remained below baseline levels for the entire 40-min observation period (Celiberti et al., 1997).

Beyond benefits associated with stereotypic behavior, research also suggests that single bouts of exercise might be effective in enhancing classroom performance for children with ASD. Rosenthal-Malek and Mitchell (1997) observed enhancements in appropriate responding and task completion in a mock classroom environment following a 20-min bout of moderately intense jogging, relative to following $20 \mathrm{~min}$ of academic instruction, in a sample of five adolescents with autism. Similarly, Kern, Koegel, Dyer, Blew, and Fenton (1982) examined the effect of single bouts of physical activity on classroom behavior in a sample of seven preadolescent children with autism using a simultaneous-treatments design occurring over a 21-day span. Findings revealed that 15-20 min of moderate intensity jogging reduced off-task behaviors and increased compliance with instructions relative to baseline measures (Kern et al., 1982). Although the small sample sizes of these investigations limit the generalizability of findings, repeatedly 
examining the effects of exercise within the same participant provides support for the stability of the behavioral benefits incurred by physical activity. Given the consistency of the observed findings, single bouts of moderately intense aerobic activity appear to be effective in reducing stereotypical behaviors and enhancing classroom behaviors in children with ASD.

Despite evidence that single bouts of aerobic physical activity benefit children with ASD, current educational practice may limit opportunities for these children to be active during school. Similar to educational practices used with children possessing other developmental disabilities, physical activity opportunities such as physical education and recess are often reduced or eliminated for children with ASD to provide additional classroom instruction (Pan, 2008). In some cases academic professionals treat physical activity opportunities only as rewards for positive classroom behavior. However, beyond failing to utilize physical activity to mitigate problematic behaviors, limiting physical activity time also limits opportunity for children with ASD to socialize with their peers (Pan, Tsai, \& Hsieh, 2011). Physical activity time may offer the best opportunity to reinforce social skills, yet a growing body of research suggests a negative feedback loop for children with ASD, with failures to socialize resulting in them removing themselves from the few physical activity opportunities that are available (Pan et al., 2011). Indeed, research using objective accelerometer-based measures shows children with ASD to engage in less physical activity during inclusive recess settings than their peers (Pan, 2008).

\section{ASD and Chronic Physical Activity Behaviors}

Beyond the influence of a single bout of physical activity, a recent metaanalysis of 16 investigations suggested that repeated bouts of exercise result in more persistent improvements in social skills and reductions in stereotypical behaviors in children with ASD (Sowa \& Meulenbroek, 2012). Utilizing a 10week water-based exercise program, Pan (2010) observed reductions in antisocial behaviors in a sample of 16 preadolescent children with ASD as well as parent-reported improvements in their child's self-confidence and selfefficacy toward social and athletic opportunities. Importantly, these improvements persisted for 10 weeks following the intervention. These findings are consistent with the observations of Duronijić and Válková (2010), who used qualitative and quantitative methodologies to examine the effects of $60 \mathrm{~min}$ of physical activity twice a week for 8 weeks on children with ASD. The intervention resulted in improvements in both motor and social skills. Chronic engagement in physical activity also appears to have implications for classroom behaviors within this population. Nicholson, Kehle, Bray, and Van Heest (2011) observed improvements in academic engagement and participation in a sample of four preadolescent males with ASD following a 
5-week jogging intervention. Collectively, these findings speak to the value of sustained physical activity engagement by children with ASD.

\section{Challenges and Limitations of Promoting Physical Activity in Children With ASD}

Although the research literature suggests a beneficial relation between physical activity and ASD symptomology, there are a number of limitations that present barriers to translating this work to the promotion of physical activity in clinical practice. One limitation is that most investigators only characterize their participants as falling within the broad diagnostic umbrella of ASD. There is substantial heterogeneity within this diagnostic classification, with some children exhibiting high functioning behaviors with Autistic tendencies and others displaying more severe symptomologies. It may be beneficial to parse the effects of physical activity in relation to specific characteristics of the sample population based on DSM- 5 criteria. For example, DSM-5 severity specifies indicating the severity of primary symptoms should be included, as well as data indicating other dimensions of the spectrum such as level of intellectual functioning, degree of language impairment, association with specific primary genetic or medical disorder, and the presence of additional comorbid features such as inattention or anxiety. Though extant work has demonstrated remarkably similar positive benefits of physical activity, as research within this area progresses it is necessary to more precisely classify participants and employ larger sample sizes to allow for confident generalization of findings.

Despite the benefits associated with physical activity, getting children with ASD to engage in exercise can be challenging. Obrusnikova and Miccinello (2012) identified a series of factors that parents perceived as impacting the physical activity participation of their children with ASD. The primary perceived barriers to physical activity-identified by over two-thirds of the respondents-were psychosocial (i.e., negative affective reactions, decreased engagement, teasing/bullying, social isolation). This likely stems from children with ASD limiting their engagement in physical activity or preferentially engaging in more solitary sedentary activities because of their lack of social success in game-playing (Pan et al., 2011). Thus, research into how to specifically engage children with ASD in physical activity is necessary because a child who is unwilling to engage in physical activity cannot incur the associated benefits.

Although group-based physical activity intervention is intuitively appealing for ASD, the efficacy of such treatment strategies is not yet fully known. Some insight can be gleaned from a recent meta-analysis, which parsed interventions into those of a solitary nature and those with more than one participant and clear interaction amongst participants (Sowa \& Meulenbroek, 2012). Contrary to a priori expectations, findings indicated 
that solitary interventions produced better results. Group-based interventions resulted in a $36 \%$ improvement in motor skills and a $26 \%$ improvement in social skills, whereas solitary interventions showed improvements of $48 \%$ and $71 \%$, respectively (Sowa \& Meulenbroek, 2012). One interpretation of these findings is that solitary interventions may offer the advantage of individual tailoring to match the specific needs of the child while avoiding potential sources of interpersonal stress (i.e., difficulties in communicating with a group and unpredictable events that result in perceived lack of control). Additionally, perhaps these solitary interventions allow for more expressive communications resulting from the formation of deeper interpersonal bonds between the participant and intervention leader (Sowa \& Meulenbroek, 2012). However, the group-based investigations included within this metaanalysis all utilized very few participants and did not intentionally program for interaction between participants. Thus, further research is necessary to determine if group-based physical activity interventions can be constructed in ways that increase participation and improve results. Finally, a greater understanding of the specific dose-response relationship between physical activity and ASD symptomology-including identification of the most effective mode, frequency, intensity, and duration of physical activity-will be key to establishing physical activity as a tool in the treatment of ASD in both practice and policy (Celiberti et al., 1997; Kern et al., 1984).

\section{DEVELOPMENTAL DISORDER ETIOLOGY AND PHYSICAL ACTIVITY}

The conceptualization of developmental disorders has been moving away from categorical and toward a dimensional nosology, in part because of the substantial comorbidity of symptoms among disorders (Tannock, 2013). In particular, symptoms of inattention and hyperactivity are frequently seen not only among children with ADHD, but also with ASD (Grzadzinski et al., 2011; Reiersen \& Todd, 2008), dyslexia (Boada, Willcutt, \& Pennington, 2012), mathematics disability (Geary \& Hoard, 2005), as well as a wide variety of externalizing and internalizing disorders (Yoshimasu et al., 2012). The prevalence of comorbid ADHD in individuals with a primary diagnosis of an ASD ranges from $28 \%$ to $50 \%$ in population- and community-based studies (Montes \& Halterman, 2007; Ronald, Simonoff, Kuntsi, Asherson, \& Plomin, 2008; Simonoff, Taylor et al., 2008). The frequent presence of impairment in all three ASD domains of social deficits, communication, and stereotyped behaviors in individuals with an ADHD diagnosis has also been noted (Reiersen \& Todd, 2008; Santosh \& Mijovic, 2004). Given the comorbidity of ADHD symptoms with so many other disorders, future research should begin to explore how both acute and chronic physical activity may modulate the symptomology and underlying etiology among these disorders. 
Understanding relations between physical activity and specific developmental disorders may also provide a means of targeting underlying etiologies. Although speculative, if physical activity selectively benefits a subset of developmental disorders then it may be possible to use physical activity as part of the diagnostic process or at least as a treatment option for a subset of symptomologies. In particular, the staggering variety of endotypes and phenotypes for autism has made it difficult to find common neural pathways that can adequately explain the spectrum characteristics in a unified way. Whereas the neurobiological mechanisms associated with ADHD and ASD are still not fully understood (Konrad \& Eikoff, 2010; Schaaf \& Zoghbi, 2011), it is apparent that there is some overlap in functional dysregulations in the brain for these disorders. Indeed, neuroimaging studies have indicated similar patterns of dysregulation for both ADHD and ASD in the prefrontal cortex (Just, Cherkassky, Keller, Kana, \& Minshew, 2007; Smith, Taylor, Brammer, Halari, \& Rubia, 2008), anterior cingulate cortex (Kana, Keller, Minshew, \& Just, 2007; Smith, Taylor et al., 2008), and large-scale neural networks such as the default-mode network (Assaf et al., 2010; Castellanos et al., 2008) and fronto-parietal circuit (Castellanos \& Proal, 2012; Kana et al., 2007). Consonant with such impairments across neural regions and networks involved in regulating goal-directed behavior, deficits in cognitive controlparticularly inhibition-are characteristic of children with ADHD and are common in children with autism (Geurts, Verté, Oosterlaan, Roeyers, \& Sergeant, 2004; Nydén, Gillberg, Hjelmquist, \& Heiman, 1999; Pennington \& Ozonoff, 1996).

Previous research across the lifespan has shown physical activity and cognition to be more strongly associated for aspects of cognitive control than for other aspects of cognition (Colcombe \& Kramer, 2003; Hall, Smith, \& Keele, 2001; Hillman, Buck et al., 2009; Kamijo et al., 2011; Kramer, Colcombe, McAuley, Scalf, \& Erickson, 2005; Kramer et al., 1999; Pontifex et al., 2011). Accordingly, physical activity behaviors may be particularly salient for neural systems underlying aspects of cognitive control (see Hillman, Erickson, \& Kramer, 2008 for a review). Indeed, individuals with greater chronic physical activity participation and aerobic fitness levels show both structural and functional changes within the brain (see Chapter 3) characterized by increased tissue volume in the prefrontal and temporal cortices (Colcombe et al., 2004, 2006), portions of the basal ganglia (Chaddock, Erickson, Prakash, VanPatter et al., 2010), and the hippocampus (Chaddock, Erickson, Prakash, Kim et al., 2010). They also show a greater ability to recruit neural resources in the frontal and parietal regions (Chaddock et al., 2012), and increased coherence across the default-mode and fronto-parietal networks in association with chronic exercise training (Voss et al., 2010). Because there appears to be some specificity of physical activity on these neural systems, populations that exhibit symptomologies 
arising from dysregulation of these cognitive systems and processes may benefit from physical activity interventions.

Endophenotypic models have emerged as a method for describing the many variations in presentation of autism spectrum disorders. Whereas some ASD-related syndromes can be clearly mapped to specific genes (e.g., 15q duplication, 22q deletion, Angelman syndrome, and Fragile X; Abrahams \& Geschwind, 2008), autism has also been linked to in utero toxins such as sodium valproate-used to control seizures (Christensen et al., 2013), low-birth weight (Johnson et al., 2010), and hundreds of de novo genetic mutations (Schaaf \& Zoghbi, 2011). Moreover, approximately $70 \%$ of children with ASD have cases considered idiopathic, with no known cause associated (Schaaf \& Zoghbi, 2011). Despite this heterogeneity in potential etiology, genetic markers for impaired transport of dopaminergic neurotransmitters (DAT1) and dysregulated brain-derived neurotrophic factor expression (BDNF) have been implicated across a number of developmental disorders including both ASD (Cheng et al., 2010; Previc, 2007) and ADHD (Gadow, Roohi, DeVincent, Kirsch, \& Hatchwell, 2009; Li, Sham, Owen, \& He, 2006). Dysregulation of these genetic markers have been linked to problems in attention and motivation in adults with ADHD (Shim et al., 2008; Volkow, Wang, Newcorn, et al., 2010) and may in part explain problems with inattention to low salience tasks such as schoolwork and why novel events and changing rewards assist children with ADHD to stay focused. Pharmacological treatments using psychostimulants for ADHD (e.g., methylphenidate) and atypical antipsychotics for ASD (e.g., resperidone) both exhibit mechanisms of action that serve to regulate the release of neurotransmitters such as dopamine (Antshel, Hargrave, Simonescu, et al., 2011) as well as modulate BDNF expression (Tan, Zhou, Cao, Zou, \& Zhang, 2005). Although there is evidence to suggest that dopamine expression may be modulated by exercise (Vucckovic et al., 2010), BDNF might provide a more promising mechanism by which physical activity benefits these developmental disorders. A substantial body of literature has implicated BDNF in exercise-induced enhancements in cognition (see GomezPinilla \& Hillman, 2013 for a review). Accordingly, a promising avenue for future research may be to begin examining the extent to which physical activity may modulate BDNF expression within these developmental disorders and how these modulations relate to overt symptomologies.

Although this review has focused on the relationship between physical activity behavior and developmental disorders, such behaviors do not occur in isolation of other lifestyle factors which may modulate-or perhaps mediate -these relationships. As highlighted in Chapter 4 of this monograph, physical activity, obesity, and nutrition are highly related constructs which all appear to influence cognition. Further, an emerging literature indicates that nutritional deficiencies may partly underlie aspects of ADHD and ASD. For example, a recent systematic review of the literature suggests that vitamin D 
deficiency may function as an environmental trigger for some endotypes of ASD (Kočovská, Fernell, Billstedt, Minnis, \& Gillberg, 2012). Also, findings from a 3-month intervention indicate that supplementation of flax oil and vitamin $\mathrm{C}$ reduced hyperactivity in a sample of 30 children with ADHD (Joshi et al., 2006), though further research is necessary to determine if the reductions stemmed from the supplementation or maturational processes. No placebo control group was included in the study. Beyond vitamin deficiencies, abnormal fatty acid and membrane phospholipid metabolism are indicated within neurodevelopmental disordered populations. Preadolescent boys with ADHD have been shown to exhibit reduced essential fatty acids, such as DHA, relative to typically developing boys (Stevens et al., 1995) and supplementation of Omega-3 fatty acids in a small pilot randomized control trial reduced symptomatic behaviors in a sample of seven children with ASD over a 6-week intervention relative to a similarly sized placebo control group (Amminger et al., 2007).

Nutritional quality is another promising area of research in understanding the relation between physical health and cognition in these clinical populations. For example, in a sample of 1,172 adolescents followed from gestation to 14 years of age as a part of the Western Australian Pregnancy Cohort (Raine) Study, individuals with a diet high in total fat, saturated fat, refined sugars, and sodium were more likely to have an ADHD diagnosis than individuals engaging in healthier dietary patterns (Howard et al., 2011). Consuming large quantities of takeout foods, red or processed meats, high-fat dairy products and soft drinks was associated with a greater likelihood of ADHD diagnosis relative to those who consumed these items less frequently. Similarly, Evans et al. (2012) observed that children with ASD consume greater quantities of energy-dense foods than typically developing children, eating $33 \%$ more snack foods and drinking $50 \%$ more sweetened beverages. Collectively, these findings provide emerging support for the consideration of nutritional health as an important factor in understanding the underlying etiology of these developmental disorders. As interest in the effects of physical activity on developmental disorders continues to grow, it will be increasingly important to understand how physical health factors such as diet, obesity, and physical activity inter-relate in these populations as well as in typically developing populations. By taking a more integrative approach targeting multiple aspects of physical health, the efficacy of such interventions for treating symptomology associated with these disorders may be bolstered.

\section{CONCLUSION}

An emerging literature points to physical activity as a potential tool to understand and treat developmental disorders such as ADHD, ASD, and 
others. This knowledge base has benefited from research at the intersection of cognitive neuroscience and kinesiology that has flourished over the last several decades. However, as this area of science continues to progress and draw interest it will become increasingly worthwhile to integrate areas of research relative to counseling, educational and clinical psychology, educational administration, nutrition, special education, and teacher education. Such collaborations will enable research in this area to capitalize on existing interdisciplinary initiatives and provide the necessary evidence for the formation of educational policies and clinical practices which may utilize physical activity and overall physical health as a means of enhancing brain health and cognition during development. However, further research is necessary across the range of developmental disorders to clarify the generalizability of beneficial physical activity and health interventions across populations, determine the transience of such benefits, and assess timing and dosage issues relative to stages of human development.

\section{REFERENCES}

Abbeduto, L., Seltzer, M. M., Shattuck, P., Krauss, M. W., Orsmond, G., \& Murphy, M. M. (2004). Psychological well-being and coping in mothers of youths with Autism, Down Syndrome, or Fragile X Syndrome. American Journal on Mental Retardation, 109, 237-254.

Abrahams, B. S., \& Geschwind, D. H. (2008). Advances in autism genetics: On the threshold of a new neurobiology. Nature Reviews Genetics, 9(5), 341-355.

Albrecht, B., Brandeis, D., Uebel, H., Heinrich, H., Mueller, U. C., Hasselhorn, M., et al. (2008). Action monitoring in boys with attention-deficit/hyperactivity disorder, their nonaffected siblings, and normal control subjects: Evidence for an endophenotype. Biological Psychiatry, 64, 615-625. doi: 10.1016/j.biopsych.2007.12.016

American Psychiatric Association. (2013). Diagnostic and statistical manual of mental disorders (5th ed.). Washington, DC: American Psychiatric Association.

Amminger, G. P., Berger, G. E., Schäfer, M. R., Klier, C., Friedrich, M. H., \& Feucht, M. (2007). Omega-3 fatty acids supplementation in children with Autism: A double-blind randomized, placebo-controlled pilot study. Biological Psychiatry, 61, 551-553. doi: 10.1016/j.biopsych.2006.05.007

Antshel, K. M., Hargrave, T. M., Simonescu, M., Kaul, P., Hendricks, K., \& Faraone, S. V. (2011). Advances in understanding and treating ADHD. BMC Medicine, 9(1), 72.

Applegate, B., Lahey, B. B., Hart, E. L., Biederman, J., Hynd, G. W., Barkley, R. A., et al. (1997). Validity of the age-of-onset criterion for ADHD: A report from the DSM-IV field trials. Journal of the American Academy of Child E Adolescent Psychiatry, 36, 1211-1221. doi: 10.1097/ 00004583-199709000-00013

Assaf, M., Jagannathan, K., Calhoun, V. D., Miller, L., Stevens, M. C., Sahl, R., et al. (2010). Abnormal functional connectivity of default mode sub-networks in autism spectrum disorder patients. Neuroimage, 53, 247-256. doi: 10.1016/j.neuroimage. 2010.05.067 
Azrin, N. H., Ehle, C. T., \& Beaumont, A. L. (2006). Physical exercise as a reinforcer to promote calmness of an ADHD child. Behavior Modification, 30, 564-570. doi: 10.1177/ 0145445504267952

Baio, J. (2012). Prevalence of Autism Spectrum Disorders: Autism and Developmental Disabilities Monitoring Network, 14 Sites, United States, 2008. Morbidity and Mortality Weekly Report. Surveillance Summaries. Volume 61, Number 3. Centers for Disease Control and Prevention.

Banaschewski, T., Ruppert, S., Tannock, R., Albrecht, B., Becker, A., Uebel, H., et al. (2006). Colour perception in ADHD. Journal of Child Psychology And Psychiatry, 47, 568-572.

Barkley, R. A. (1997). Behavioral inhibition, sustained attention, and executive functions: Constructing a unifying theory of ADHD. Psychological Bulletin, 121, 65-94. doi: 10.1037/ 0033-2909.121.1.65

Barkley, R. A., DuPaul, G.J., \& McMurray, M. B. (1990). Comprehensive evaluation of attention deficit disorder with and without hyperactivity as defined by research criteria. Journal of Consulting and Clinical Psychology, 58, 775-789. doi: 10.1037/0022-006X.58.6.775

Barkley, R. A., Guevremont, D. C., Anastopoulos, A. D., DuPaul, G. J., \& Shelton, T. L. (1993). Driving-related risks and outcomes of attention deficit hyperactivity disorder in adolescents and young adults: A 3-to 5-year follow-up survey. Pediatrics, 92, 212-218.

Bar-Or, O. (1983). Pediatric sports medicine for the practitioner: From physiologic principles to clinical applications. New York: Springer-Verlag.

Berger, I., Dor, T., Nevo, Y., \& Goldzweig, G. (2008). Attitudes toward attention-deficit hyperactivity disorder (ADHD) treatment: Parents and childrens perspectives. Journal of Child Neurology, 23, 1036-1042. doi: 10.1177/0883073808317726

Biederman, J., Wilens, T. E., Mick, E., Faraone, S. V., \& Spencer, T. (1998). Does attentiondeficit hyperactivity disorder impact the developmental course of drug and alcohol abuse and dependence? Biological Psychiatry, 44, 269-273. doi: 10.1016/S0006-3223(97)00406-X

Bloom, B., Cohen, R. A., \& Freeman, G. (2010). Summary health statistics for U.S. children: National health interview survey 2009. Vital and Health Statistics, 10, 1-82.

Boada, R., Willcutt, E. G., \& Pennington, B. F. (2012). Understanding the comorbidity between dyslexia and attention-deficit/hyperactivity disorder. Topics in Language Disorders, 32, 264284. doi: 10.1097/TLD.0b013e31826203ac

Booth, J. E., Carlson, C. L., \& Tucker, D. M. (2007). Performance on a neurocognitive measure of alerting differentiates ADHD combined and inattentive subtypes: A preliminary report. Archives of Clinical Neuropsychology, 22, 423-432. doi: 10.1016/j.acn.2007.01.017

Botvinick, M. M., Braver, T. S., Barch, D., Carter, C. S., \& Cohen, J. D. (2001). Conflict monitoring and cognitive control. Psychological Review, 108, 624-652.

Bracken, B. A., \& Boatwright, B. S. (2005). Clinical assessment of attention deficit-child/adult professional manual. Lutz, FL: Psychological Assessment Resources, Inc.

Brown, R. T., \& Pacini, J. N. (1989). Perceived family functioning, marital status, and depression in parents of boys with attention deficit disorder. Journal of Learning Disabilities, 22, 581587. doi: 10.1177/002221948902200911

Castellanos, F. X., Margulies, D. S., Kelly, C., Uddin, L. Q., Ghaffari, M., Kirsch, A., et al. (2008). Cingulate-precuneus interactions: A new locus of dysfunction in adult attention-deficit/ hyperactivity disorder. Biological Psychiatry, 63, 332-337. doi: 10.1016/j.biopsych.2007.06.025

Castellanos, F. X., Marvasti, F. F., Ducharme, J. L., Walter, J. M., Israel, M. E., Krain, A., et al. (2000). Executive function oculomotor tasks in girls with ADHD. Journal of the American Academy of Child Eं Adolescent Psychiatry, 39, 644-650. 
Castellanos, F. X., \& Proal, E. (2012). Large-scale brain systems in ADHD: Beyond the prefrontal-striatal model. Trends in Cognitive Science, 16, 17-26.

Castelli, D. M., Hillman, C. H., Buck, S. M., \& Erwin, H. E. (2007). Physical fitness and academic achievement in third- and fifth-grade students. Journal of Sport $\mathcal{E}$ Exercise Psychology, 29, 239-252.

Celiberti, D. A., Bobo, H. E., Kelly, K. S., Harris, S. L., \& Handleman, J. S. (1997). The differential and temporal effects of antecedent exercise on the self-stimulatory behavior of a child with autism. Research in Developmental Disabilities, 18, 139-150. doi: 10.1016/S08914222(96) 00032-7

Chaddock, L., Erickson, K. I., Prakash, R. S., Kim, J. S., Voss, M. W., VanPatter, M., et al. (2010). A neuroimaging investigation of the association between aerobic fitness, hippocampal volume, and memory performance in preadolescent children. Brain Research, 1358, 172183. doi: $10.1016 /$ j.brainres.2010.08.049

Chaddock, L., Erickson, K. I., Prakash, R. S., VanPatter, M., Voss, M. W., Pontifex, M. B., et al. (2010). Basal ganglia volume is associated with aerobic fitness in preadolescent children. Developmental Neuroscience, 32, 249-256. doi: 10.1159/000316648

Chaddock, L., Erickson, K. I., Prakash, R. S., Voss, M. W., VanPatter, M., Pontifex, M. B., et al. (2012). A functional MRI investigation of the association between childhood aerobic fitness and neurocognitive control. Biological Psychology, 89, 260-268. doi: 10.1016/j. biopsycho.2011.10.017

Cheng, Y., Chou, K. H., Chen, I. Y., Fan, Y. T., Decety, J., \& Lin, C. P. (2010). Atypical development of white matter microstructure in adolescents with autism spectrum disorders. Neuroimage, 50(3), 873-882.

Christensen, J., Grønborg, T. K., Sørensen, M. J., Schendel, D., Parner, E. T., Pedersen, L. H., \& Vestergaard, M. (2013). Prenatal valproate exposure and risk of autism spectrum disorders. JAMA, 309(16), 1696-1703.

Colcombe, S. J., Erickson, K. I., Scalf, P. E., Kim, J. S., Prakash, R., McAuley, E. M., et al. (2006). Aerobic exercise training increases brain volume in aging humans. The Journals of Gerontology Series A: Biological Sciences and Medical Sciences, 61, 1166-1170.

Colcombe, S. J., \& Kramer, A. F. (2003). Fitness effects on the cognitive function of older adults: A meta-analytic study. Psychological Science, 14, 125-130. doi: 10.1111/1467-9280.t01-101430

Colcombe, S. J., Kramer, A. F., Erickson, K. I., Scalf, P., McAuley, E., Cohen, N. J., et al. (2004). Cardiovascular fitness, cortical plasticity, and aging. Proceedings of the National Academy of Sciences, 101, 3316-3321. doi: 10.1073/pnas.0400266101

Craft, D. H. (1983). Effect of prior exercise on cognitive performance tasks by hyperactive and normal young boys. Perceptual and Motor Skills, 56, 979-982.

Crone, E. A., Jennings, J. R., \& Van Der Molen, M. W. (2003). Sensitivity to interference and response contingencies in attention-deficit/hyperactivity disorder. Journal of Child Psychology and Psychiatry, 44, 214-226. doi: 10.1111/1469-7610.00115

Davidson, M. C., Amso, D., Anderson, L. C., \& Diamond, A. (2006). Development of cognitive control and executive functions from 4 to 13 years: Evidence from manipulations of memory, inhibition, and task switching. Neuropsychologia, 44, 2037-2078. doi: 10.1016/j. neuropsychologia.2006.02.006

Department of Health and Human Services [DHHS] and Department of Education [DOE]. (2000). Promoting better health for young people through physical activity and sports. A report to the 
President from the Secretary of Health and Human Services and the Secretary of Education. Silver Spring, MD: Centers for Disease Control.

dosReis, S., Zito, J. M., Safer, D. J., Soeken, K. L., Mitchell, J. W., Jr., \& Ellwood, L. C. (2003). Parental perceptions and satisfaction with stimulant medication for attentiondeficit hyperactivity disorder. Journal of Developmental $\mathcal{E}$ Behavioral Pediatrics, 24, $155-162$.

Duronijić, M., \& Válková, H. (2010). The influence of early intervention movement programs on motor skills development in preschoolers with Autism Spectrum Disorder. Acta Universitatis Palackianae Olomucensis. Gymnica, 40, 37-47.

Etscheidt, M. A., \& Ayllon, T. (1987). Contingent exercise to decrease hyperactivity. Journal of Child E Adolescent Psychotherapy, 4, 192-198.

Evans, E. W., Must, A., Anderson, S. E., Curtin, C., Scampini, R., Maslin, M., et al. (2012). Dietary patterns and body mass index in children with autism and typically developing children. Research in Autism Spectrum Disorders, 6, 399-405. doi: 10.1016/j.rasd.2011.06.014

Gadow, K. D., Roohi, J., DeVincent, C. J., Kirsch, S., \& Hatchwell, E. (2009). Association of COMT (Val158Met) and BDNF (Val66Met) gene polymorphisms with anxiety, ADHD, and tics in children with autism spectrum disorder. Journal of Autism and Developmental Disorders, 39, 1542-1551. doi: 10.1007/s10803-009-0794-4

Gapin, J., \& Etnier, J. L. (2010). The relationship between physical activity and executive function performance in children with attention-deficit hyperactivity disorder. Journal of Sport $\mathcal{E}$ Exercise Psychology, 32, 753-763.

Geary, D. C., \& Hoard, M. K. (2005). Learning disabilities in arithmetic and mathematics. In J. I. Campbell (Ed.), The handbook of mathematical cognition (pp. 253-268). New York, NY: Psychology Press.

Geurts, H. M., Verté, S., Oosterlaan, J., Roeyers, H., \& Sergeant, J. A. (2004). How specific are executive functioning deficits in attention deficit hyperactivity disorder and autism? Journal of Child Psychology and Psychiatry, 45, 836-854. doi: 10.1111/j.1469-7610.2004. 00276.x

Gomez-Pinilla, F., \& Hillman, C. H. (2013). The influence of exercise on cognitive abilities. Comprehensive Physiology, 3, 403-428. doi: 10.1002/cphy.c110063

Goyette, C. H., Conners, C. K., \& Ulrich, R. F. (1978). Normative data on Revised Conners Parent and Teacher Rating Scales. Journal of Abnormal Child Psychology, 6, 221-236. doi: 10.1007/BF00919127

Grzadzinski, R., Di Martino, A., Brady, E., Mairena, M. A., O’Neale, M., Petkova, E., et al. (2011). Examining autistic traits in children with ADHD: Does the autism spectrum extend to ADHD? Journal of Autism and Developmental Disorders, 41, 1178-1191. doi: 10.1007/s10803010-1135-3

Hall, C. D., Smith, A. L., \& Keele, S. W. (2001). The impact of aerobic activity on cognitive function in older adults: A new synthesis based on the concept of executive control. European Journal of Cognitive Psychology, 13, 279-300. doi: 10.1080/09541440126012

Hart, E. L., Lahey, B. B., Loeber, R., Applegate, B., \& Frick, P. J. (1995). Developmental change in attention-deficit hyperactivity disorder in boys: A four-year longitudinal study. Journal of Abnormal Child Psychology, 23, 729-749. doi: 10.1007/BF01447474

Hartung, C. M., Milich, R., Lynam, D. R., \& Martin, C. A. (2002). Understanding the relations among gender, disinhibition, and disruptive behavior in adolescents. Journal of Abnormal Psychology, 111, 659-664. doi: 10.1037/0021-843X.111.4.659 
Hastings, R. P., \& Johnson, E. (2001). Stress in UK families conducting intensive home-based behavioral intervention for their young child with autism. Journal of Autism and Developmental Disorders, 31, 327-336. doi: 10.1023/A:1010799320795

Hillman, C. H., Buck, S. M., Themanson, J. R., Pontifex, M. B., \& Castelli, D. M. (2009). Aerobic fitness and cognitive development: Event-related brain potential and task performance indices of executive control in preadolescent children. Developmental Psychology, 45, 114129. doi: $10.1037 / \mathrm{a} 0014437$

Hillman, C. H., Erickson, K. I., \& Kramer, A. F. (2008). Be smart, exercise your heart: Exercise effects on brain and cognition. Nature Reviews Neuroscience, 9, 58-65. doi: 10.1038/nrn2298

Hillman, C. H., Pontifex, M. B., Raine, L. B., Castelli, D. M., Hall, E. E., \& Kramer, A. F. (2009). The effect of acute treadmill walking on cognitive control and academic achievement in preadolescent children. Neuroscience, 159, 1044-1054. doi: 10.1016/j.neuroscience. 2009.01.057

Hillman, C. H., Snook, E. M., \& Jerome, G. J. (2003). Acute cardiovascular exercise and executive control function. International Journal of Psychophysiology, 48, 307-314. doi: 10.1016/S0167-8760(03)00080-1

Hogervorst, E., Riedel, W., Jeukendrup, A., \& Jolles, J. (1996). Cognitive performance after strenuous physical exercise. Perceptual and Motor Skills, 83, 479-488.

Homack, S., \& Riccio, C. A. (2004). A meta-analysis of the sensitivity and specificity of the Stroop Color and Word Test with children. Archives of Clinical Neuropsychology, 19, 725-743. doi: 10.1016/j.acn.2003.09.003

Howard, A. L., Robinson, M., Smith, G. J., Ambrosini, G. L., Piek, J. P., \& Oddy, W. H. (2011). ADHD is associated with a "Western" dietary pattern in adolescents. Journal of Attention Disorders, 15, 403-411. doi: 10.1177/1087054710365990

Iaboni, F., Douglas, V. I., \& Baker, A. (1995). Effects of reward and response costs on inhibition in ADHD children. Journal of Abnormal Psychology, 104, 232-240. doi: 10.1037/0021843X.104.1.232

Johnson, S., Hollis, C., Kochhar, P., Hennessy, E., Wolke, D., \& Marlow, N. (2010). Autism spectrum disorders in extremely preterm children. The Journal of Pediatrics, 156(4), 525531.

Jonkman, L. M., Kemner, C., Verbaten, M. N., Van Engeland, H., Kenemans, J. L., Camfferman, G., et al. (1999). Perceptual and response interference in children with attention-deficit hyperactivity disorder, and the effects of methylphenidate. Psychophysiology, 36, 419-429. doi: 10.1111/1469-8986.3640419

Joshi, K., Lad, S., Kale, M., Patwardhan, B., Mahadik, S. P., Patni, B., et al. (2006). Supplementation with flax oil and vitamin $\mathrm{C}$ improves the outcome of attention deficit hyperactivity disorder (ADHD). Prostaglandins, Leukotrienes and Essential Fatty Acids, 74, 1721. doi: $10.1016 /$ j.plefa.2005.10.001

Just, A. M., Cherkassky, V. L., Keller, T. A., Kana, R. K., \& Minshew, N. J. (2007). Functional and anatomical cortical underconnectivity in Autism: Evidence from an fMRI study of an executive function task and corpus callosum morphometry. Cerebral Cortex, 17, 951-961. doi: $10.1093 /$ cercor/bhl006

Kamijo, K., Nishihira, Y., Higashiura, T., \& Kuroiwa, K. (2007). The interactive effect of exercise intensity and task difficulty on human cognitive processing. International Journal of Psychophysiology, 65, 114-121. doi: 10.1016/j.ijpsycho.2007.04.001 
Kamijo, K., Pontifex, M. B., O’Leary, K. C., Scudder, M. R., Wu, C.-T., Castelli, D. M., et al. (2011). The effects of an afterschool physical activity program on working memory in preadolescent children. Developmental Science, 14, 1046-1058. doi: 10.1111/j.14677687.2011.01054.x

Kana, R. K., Keller, T. A., Minshew, N. J., \& Just, M. A. (2007). Inhibitory control in highfunctioning autism: Decreased activation and underconnectivity in inhibition networks. Biological Psychiatry, 62, 198-206. doi: 10.1016/j.biopsych.2006.08.004

Kern, L., Koegel, R. L., \& Dunlap, G. (1984). The influence of vigorous versus mild exercise on autistic stereotyped behaviors. Journal of Autism and Developmental Disorders, 14, 57-67. doi: $10.1007 / \mathrm{BF} 02408555$

Kern, L., Koegel, R. L., Dyer, K., Blew, P. A., \& Fenton, L. R. (1982). The effects of physical exercise on self-stimulation and appropriate responding in autistic children. Journal of Autism and Developmental Disorders, 12, 399-419. doi: 10.1007/BF01538327

Khanna, R., Madhavan, S. S., Smith, M.J., Patrick, J. H., Tworek, C., \& Becker-Cottrill, B. (2011). Assessment of health-related quality of life among primary caregivers of children with autism spectrum disorders. Journal of Autism and Developmental Disorders, 41, 1214-1227. doi: 10.1007/s10803-010-1140-6

Kim, H., Heo, H. I., Kim, D. H., Ko, I. G., Lee, S. S., Kim, S. E., et al. (2011). Treadmill exercise and methylphenidate ameliorate symptoms of attention deficit/hyperactivity disorder through enhancing dopamine synthesis and brain-derived neurotrophic factor expression in spontaneous hypertensive rats. Neuroscience Letters, 504(1), 35-39.

Kim, J., Mutyala, B., Agiovlasitis, S., \& Fernhall, B. (2011). Health behaviors and obesity among US children with attention deficit hyperactivity disorder by gender and medication use. Preventive Medicine, 52, 218-222. doi: 10.1016/j.ypmed.2011.01.003

Kirk, S. A., McCarthy, J. J., \& Kirk, W. D. (1968). Illinois test of psycholinguistic abilities. Urbana: University of Illinois Press.

Knapp, M., Romeo, R., \& Beecham, J. (2009). Economic cost of autism in the UK. Autism, 13, 317-336. doi: 10.1177/1362361309104246

Kočovská, E., Fernell, E., Billstedt, E., Minnis, H., \& Gillberg, C. (2012). Vitamin D and autism: Clinical review. Research in Developmental Disabilities, 33, 1541-1550. doi: 10.1016/j. ridd.2012.02.015

Koenig, K., White, S. W., Pachler, M., Lau, M., Lewis, M., Klin, A., et al. (2010). Promoting social skill development in children with pervasive developmental disorders: A feasibility and efficacy study. Journal of Autism and Developmental Disorders, 40, 1209-1218. doi: 10.1007/ s10803-010-0979-x

Konrad, K., \& Eickhoff, S. B. (2010). Is the ADHD brain wired differently? A review on structural and functional connectivity in attention deficit hyperactivity disorder. Human Brain Mapping, 31(6), 904-916.

Konrad, K., Neufang, S., Hanisch, C., Fink, G. R., \& Herpertz-Dahlmann, B. (2006). Dysfunctional attentional networks in children with attention deficit/hyperactivity disorder: Evidence from an event-related functional magnetic resonance imaging study. Biological Psychiatry, 59, 643-651. doi: 10.1016/j.biopsych.2005.08.013

Kramer, A. F., Colcombe, S. J., McAuley, E., Scalf, P. E., \& Erickson, K. I. (2005). Fitness, aging and neurocognitive function. Neurobiology of Aging, 26, 124-127. doi: 10.1016/j. neurobiolaging.2005.09.009 
Kramer, A. F., Hahn, S., Cohen, N. J., Banich, M. T., McAuley, E., Harrison, C. R., et al. (1999). Ageing, fitness and neurocognitive function. Nature, 400, 418-419. doi: 10.1038/22682

Lang, R., Koegel, L. K., Ashbaugh, K., Regester, A., Ence, W., \& Smith, W. (2010). Physical exercise and individuals with autism spectrum disorders: A systematic review. Research in Autism Spectrum Disorders, 4, 565-576. doi: 10.1016/j.rasd.2010.01.006

Li, D., Sham, P. C., Owen, M. J., \& He, L. (2006). Meta-analysis shows significant association between dopamine system genes and attention deficit hyperactivity disorder (ADHD). Human Molecular Genetics, 15, 2276-2284. doi: 10.1093/hmg/dd1152

Lichtman, S., \& Poser, E. G. (1983). The effects of exercise on mood and cognitive functioning. Journal of Psychosomatic Research, 27, 43-52.

Loeber, R., Green, S. M., Lahey, B. B., Christ, M. G., \& Frick, P. J. (1992). Developmental sequences in the age of onset of disruptive child behaviors. Journal of Child and Family Studies, 1, 21-41. doi: 10.1007/BF01321340

Loney, J., \& Milich, R. (1982). Hyperactivity, inattention, and aggression in clinical practice. In M. Wolrich \& D. K. Routh (Eds.), Advances in developmental and behavioral pediatrics (Vol. 3, pp. 113-147). Greenwich, CT: JAI Press.

Martel, M. M., von Eye, A., \& Nigg, J. (2012). Developmental differences in structure of attention-deficit/hyperactivity disorder (ADHD) between childhood and adulthood. International Journal of Behavioral Development, 36(4), 279-292.

McKune, A. J., Pautz, J., \& Lombard, J. (2003). Behavioural response to exercise in children with attention-deficit/hyperactivity disorder. Sports Medicine, 15, 17-21.

Medina, J. A., Netto, T. L., Muszkat, M., Medina, A. C., Botter, D., Orbetelli, R., et al. (2010). Exercise impact on sustained attention of ADHD children, methylphenidate effects. ADHD Attention Deficit Hyperactivity Disorders, 2, 49-58.

Meyer, D. E., \& Kieras, D. E. (1997). A computational theory of executive cognitive processes and multiple-task performance: Part 1. Basic mechanisms. Psychological Review, 104, $3-65$.

Miyake, A., Friedman, N. P., Emerson, M. J., Witzki, A. H., \& Howerter, A. (2000). The unity and diversity of executive functions and their contributions to complex "frontal lobe" tasks: A latent variable analysis. Cognitive Psychology, 41, 49-100.

Moll, G. H., Hause, S., Rüther, E., Rothenberger, A., \& Huether, G. (2001). Early methylphenidate administration to young rats causes a persistent reduction in the density of striatal dopamine transporters. Journal of Child and Adolescent Psychopharmacology, 11, 15-24. doi: 10.1089/104454601750143366

Montes, G., \& Halterman, J. S. (2007). Psychological functioning and coping among mothers of children with autism: A population-based study. Pediatrics, 119, e1040-e1046. doi: 10.1542/peds.2006-2819

Nicholson, H., Kehle, T. J., Bray, M. A., \& Van Heest, J. (2011). The effects of antecedent physical activity on the academic engagement of children with autism spectrum disorder. Psychology in the Schools, 48, 198-213. doi: 10.1002/pits.20537

Noe, L., \& Hankin, C. S. (2001). Health outcomes of childhood attention-deficit/hyperactivity disorder (ADHD): Health care use and work status of caregivers. Value in Health, 4, 140141. doi: 10.1046/j.1524-4733.2001.40202-196.x

Norman, D. A., \& Shallice, T. (1986). Attention to action: Willed and automatic control of behavior. In R. J. Davidson, G. E. Schwartz, \& D. Shapiro (Eds.), Consciousness and selfregulation: Advances in research and theory (Vol. 4, pp. 1-18). New York: Plenum. 
Nydén, A., Gillberg, C., Hjelmquist, E., \& Heiman, M. (1999). Executive function/attention deficits in boys with Asperger syndrome, attention disorder and reading/writing disorder. Autism, 3, 213-228. doi: 10.1177/1362361399003003002

Obrusnikova, I., \& Miccinello, D. L. (2012). Parent perceptions of factors influencing afterschool physical activity of children with autism spectrum disorders. Adapted Physical Activity Quarterly, 29, 63-80.

Pan, C.-Y. (2008). Objectively measured physical activity between children with Autism spectrum disorders and children without disabilities during inclusive recess settings in Taiwan. Journal of Autism and Developmental Disorders, 38, 1292-1301. doi: 10.1007/s10803007-0518-6

Pan, C.-Y. (2010). Effects of water exercise swimming program on aquatic skills and social behaviors in children with autism spectrum disorders. Autism, 14, 9-28. doi: 10.1177/ 1362361309339496

Pan, C.-Y., \& Frey, G. C. (2006). Physical activity patterns in youth with autism spectrum disorders. Journal of Autism and Developmental Disorders, 36, 597-606. doi: 10.1007/s10803006-0101-6

Pan, C.-Y., Tsai, C.-L., \& Hsieh, K.-W. (2011). Physical activity correlates for children with autism spectrum disorders in middle school physical education. Research Quarterly for Exercise and Sport, 82, 491-498. doi: 10.5641/027013611X13275191443982

Panksepp, J., Burgdorf, J., Turner, C., \& Gordon, N. (2003). Modeling ADHD-type arousal with unilateral frontal cortex damage in rats and beneficial effects play therapy. Brain and Cognition, 52, 97-105. doi: 10.1016/S0278-2626(03)00013-7

Pastor, P. N., \& Reuben, C. A. (2008). Diagnosed attention deficit hyperactivity disorder and learning disability: United States, 2004-2006. Vital and health statistics. Series 10, Data from the National Health Survey, 237, 1.

Pennington, B. F., \& Ozonoff, S. (1996). Executive functions and developmental psychopathology. Journal of Child Psychology and Psychiatry, 37, 51-87. doi: 10.1111/ j.1469-7610.1996.tb01380.x

Polanczyk, G., Silva de Lima, M., Horta, B. L., Biederman, J., \& Rohde, L. A. (2007). The worldwide prevalence of ADHD: A systematic review and metaregression analysis. American Journal of Psychiatry, 164, 942-948.

Pomerleau, O. F., Downey, K. K., Stelson, F. W., \& Pomerleau, C. S. (1995). Cigarette smoking in adult patients diagnosed with attention deficit hyperactivity disorder. Journal of Substance Abuse, 7, 373-378. doi: 10.1016/0899-3289(95)90030-6

Pontifex, M. B., Raine, L. B., Johnson, C. R., Chaddock, L., Voss, M. W., Cohen, N. J., et al. (2011). Cardiorespiratory fitness and the flexible modulation of cognitive control in preadolescent children. Journal of Cognitive Neuroscience, 23, 1332-1345. doi: 10.1162/ jocn.2010.21528

Pontifex, M. B., Saliba, B. J., Raine, L. B., Picchietti, D. L., \& Hillman, C. H. (2013). Exercise improves behavioral, neurocognitive, and scholastic performance in children with ADHD. Journal of Pediatrics, 162, 543-551. doi: 10.1016/j.jpeds.2012.08.036

Pontifex, M. B., Scudder, M. R., Drollette, E. S., \& Hillman, C. H. (2012). Fit and vigilant: The relationship between sedentary behavior and failures in sustained attention during preadolescence. Neuropsychology, 26, 407-413. doi: 10.1037/a0028795

Previc, F. H. (2007). Prenatal influences on brain dopamine and their relevance to the rising incidence of autism. Medical Hypotheses, 68, 46-60. doi: 10.1016/j.mehy.2006.06.041 
Reiersen, A. M., \& Todd, R. D. (2008). Co-occurrence of ADHD and autism spectrum disorders: Phenomenology and treatment. Expert Review of Neurotherapeutics, 8, 657-669. doi: 10.1586/14737175.8.4.657

Rice, C. (2009). Prevalence of autism spectrum disorders: Autism and developmental disabilities monitoring network, United States, 2006. Department of Health and Human Services, Centers for Disease Control and Prevention.

Robinson, A. M., Hopkins, M. E., \& Bucci, D. J. (2011). Effects of physical exercise on ADHDlike behavior in male and female adolescent spontaneously hypertensive rats. Developmental Psychobiology, 53, 383-390. doi: 10.1002/dev.20530

Ronald, A., Simonoff, E., Kuntsi, J., Asherson, P., \& Plomin, R. (2008). Evidence for overlapping genetic influences on autistic and ADHD behaviours in a community twin sample. Journal of Child Psychology and Psychiatry, 49, 535-542. doi: 10.1111/j.1469-7610.2007.01857.x

Rosenthal-Malek, A., \& Mitchell, S. (1997). Brief report: The effects of exercise on the selfstimulatory behaviors and positive responding of adolescents with autism. Journal of Autism and Developmental Disorders, 27, 193-202. doi: 10.1023/A:1025848009248

Santosh, P. J., \& Mijovic, A. (2004). Social impairment in hyperkinetic disorder. European Child \& Adolescent Psychiatry, 13, 141-150. doi: 10.1007/s00787-004-0372-4

Schaaf, C. P., \& Zoghbi, H.Y. (2011). Solving the autism puzzle a few pieces at a time. Neuron, 70, 806-808. doi: 10.1016/j.neuron.2011.05.025

Schachar, R., Mota, V. L., Logan, G. D., Tannock, R., \& Klim, P. (2000). Confirmation of an inhibitory control deficit in attention-deficit/hyperactivity disorder. Journal of Abnormal Child Psychology, 28, 227-235.

Shim, S.-H., Hwangbo, Y., Kwon, Y.-J., Jeong, H.-Y., Lee, B.-H., Lee, H.-J., et al. (2008). Increased levels of plasma brain-derived neurotrophic factor (BDNF) in children with attention deficit-hyperactivity disorder (ADHD). Progress in Neuro-Psychopharmacology E Biological Psychiatry, 32, 1824-1828. doi: 10.1016/j.pnpbp.2008.08.005

Sibley, B. A., \& Etnier, J. L. (2003). The relationship between physical activity and cognition in children: A meta-analysis. Pediatric Exercise Science, 15, 243-256.

Sibley, B. A., Etnier, J. L., \& Le Masurier, G. C. (2006). Effects of an acute bout of exercise on cognitive aspects of Stroop performance. Journal of Sport $\mathcal{E}$ Exercise Psychology, 28, 285-299.

Smith, A. L., Hoza, B., Linnea, K., McQuade, J. D., Tomb, M., Vaughn, A. J., et al. (2013). Pilot physical activity intervention reduces severity of ADHD symptoms in young children. Journal of Attention Disorders, 17, 70-82. doi: 10.1177/1087054711417395

Simonoff, E., Pickles, A., Charman, T., Chandler, S., Loucas, T., \& Baird, G. (2008). Psychiatric disorders in children with Autism Spectrum Disorders: Prevalence, comorbidity, and associated factors in a population-derived sample. Journal of the American Academy of Child $\mathcal{E}$ Adolescent Psychiatry, 47, 921-929. doi: 10.1097/CHI.0b013e318179964f

Smith, L. E., Seltzer, M. M., Tager-Flusberg, H., Greenberg, J. S., \& Carter, A. S. (2008). A comparative analysis of well-being and coping among mothers of toddlers and mothers of adolescents with ASD. Journal of Autism and Developmental Disorders, 38, 876-889. doi: 10.1007/s10803-007-0461-6

Smith, A. B., Taylor, E., Brammer, M., Halari, R., \& Rubia, K. (2008). Reduced activation in right lateral prefrontal cortex and anterior cingulate gyrus in medication-naive adolescents with attention deficit hyperactivity disorder during time discrimination. Journal of Child Psychology and Psychiatry, 49, 977-985. doi: 10.1111/j.1469-7610.2008.01870.x 
Solanto, M. V., Arnsten, A. T., \& Castellanos, F. X. (2001). Stimulant drugs and ADHD: Basic and clinical neuroscience. New York, NY: Oxford University Press.

Sowa, M., \& Meulenbroek, R. (2012). Effects of physical exercise on Autism Spectrum Disorders: A meta-analysis. Research in Autism Spectrum Disorders, 6, 46-57. doi: 10.1016/j. rasd.2011.09.001

Stevens, L. J., Zentall, S. S., Deck, J. L., Abate, M. L., Watkins, B. A., Lipp, S. R., et al. (1995). Essential fatty acid metabolism in boys with attention-deficit hyperactivity disorder. The American Journal of Clinical Nutrition, 62, 761-768.

Tan, Y. L., Zhou, D. F., Cao, L. Y., Zou, Y. Z., \& Zhang, X. Y. (2005). Decreased BDNF in serum of patients with chronic schizophrenia on long-term treatment with antipsychotics. Neuroscience Letters, 382, 27-32.

Tannock, R. (2013). Rethinking ADHD and LD in DSM-5: Proposed changes in diagnostic criteria. Journal of Learning Disabilities, 46, 5-25. doi: 10.1177/0022219412464341

Tomporowski, P. D. (2003). Cognitive and behavioral responses to acute exercise in youths: A review. Pediatric Exercise Science, 15, 348-359.

Tomporowski, P. D., Cureton, K., Armstrong, L. E., Kane, G. M., Sparling, P. B., \& MillardStafford, M. (2005). Short-term effects of aerobic exercise on executive processes and emotional reactivity. International Journal of Sport and Exercise Psychology, 3, 131-146. doi: 10.1080/1612197X.2005.9671763

Vaidya, C. J., Austin, G., Kirkorian, G., Ridlehuber, H. W., Desmond, J. E., Glover, G. H., et al. (1998). Selective effects of methylphenidate in attention deficit hyperactivity disorder: A functional magnetic resonance study. Proceedings of the National Academy of Sciences, 95, 14494-14499. doi: 10.1073/pnas.95.24.14494

Vaidya, C.J., Bunge, S. A., Dudukovic, N. M., Zalecki, C. A., Elliott, G. R., \& Gabrieli, J. D. (2005). Altered neural substrates of cognitive control in childhood ADHD: Evidence from functional magnetic resonance imaging. American Journal of Psychiatry, 162, 1605-1613. doi: 10.1176/appi.ajp.162.9.1605

Verret, C., Guay, M. C., Berthiaume, C., Gardiner, P., \& Béliveau, L. (2012). A physical activity program improves behavior and cognitive functions in children with ADHD: An exploratory study. Journal of Attention Disorders, 16, 71-80. doi: 10.1177/ 1087054710379735

Volkow, N. D., Wang, G. J., Newcorn, J. H., Kollins, S. H., Wigal, T. L., Telang, F., et al. (2010). Motivation deficit in ADHD is associated with dysfunction of the dopamine reward pathway. Molecular Psychiatry, 16(11), 1147-1154.

Voss, M. W., Prakash, R. S., Erickson, K. I., Basak, C., Chaddock, L., Kim, J. S., et al. (2010). Plasticity of brain networks in a randomized intervention trial of exercise training in older adults. Frontiers in Aging Neuroscience, 2, 1-17. doi: 10.3389/fnagi.2010.00032

Vučcković, M. G., Li, Q., Fisher, B., Nacca, A., Leahy, R. M., Walsh, J. P., et al. (2010). Exercise elevates dopamine D2 receptor in a mouse model of Parkinson's disease: In vivo imaging with [18F] fallypride. Movement Disorders, 25(16), 2777-2784.

Wechsler, D. (1974). WISC-R Wechsler Intelligence Scale for Children, Revised. New York, NY: The Psychological Corporation.

Willcutt, E. G., Doyle, A. E., Nigg, J. T., Faraone, S. V., \& Pennington, B. F. (2005). Validity of the executive function theory of attention-deficit/hyperactivity disorder: A meta-analytic review. Biological Psychiatry, 57, 1336-1346. doi: 10.1016/j.biopsych.2005.02.006 
Wilson, L. J., \& Jennings, J. N. (1996). Parents' acceptability of alternative treatments for attention-deficit hyperactivity disorder. Journal of Attention Disorders, 1, 114-121. doi: $10.1177 / 108705479600100204$

Yoshimasu, K., Barbaresi, W. J., Colligan, R. C., Voigt, R. G., Killian, J. M., Weaver, A. L., et al. (2012). Childhood ADHD is strongly associated with a broad range of psychiatric disorders during adolescence: A population-based birth cohort study. Journal of Child Psychology and Psychiatry, 53, 1036-1043. doi: 10.1111/j.1469-7610.2012.02567.x 